\title{
MALDI (Matrix Assisted Laser Desorption Ionisation): Imaging Modality for Tumour Diagnosis
}

\author{
Akshara Lenin ${ }^{1}$, Prajakta Suresh Kundekar' ${ }^{1}$, Kumar Sougata ${ }^{1}, \mathrm{~K}$ \\ yeswanth Sunny ${ }^{1}$ and Gaurav ${ }^{2 *}$ \\ ${ }^{1}$ House Surgeons, NSVK Sri Venkateshwara Dental College and Hospital, \\ Bangalore, Karnataka, India \\ ${ }^{2}$ Consultant Oral Physician and Maxillofacial Radiologist, Assistant Professor, \\ Department of Oral Medicine and Maxillofacial Radiology, NSVK Sri \\ Venkateshwara Dental College and Hospital, Bangalore, Karnataka, India \\ *Corresponding Author: Gaurav, Consultant Oral Physician and Maxillofacial \\ Radiologist, Assistant Professor, Department of Oral Medicine and \\ Maxillofacial Radiology, NSVK Sri Venkateshwara Dental College and Hospital, \\ Bangalore, Karnataka, India.
}

Received: February 23, 2021

Published: March 15, 2021

(C) All rights are reserved by Gaurav., et al.

\begin{abstract}
Background: MALDI or Matrix Assisted Laser Desorption Ionisation has emerged as a powerful, versatile imaging modality that has since its advent created ripples in the scientific community. The major reason for its success is the ability of this system to critically analyze, study the macromolecules and detect their presence in thousands of samples simultaneously. Moreover, because of its soft ionization techniques, it is now possible to study the biomolecules which would have previously decomposed due to inappropriate ionization skills. It is also the first of its kind to bring the world of mass spectrometry and the world of histology under the same banner creating a modality that is currently transforming the way we have understood the world of bioinformatics. Now it is possible to study a broad spectrum of analytes in unprecedented detail most of which until a few years ago had been completely unknown to the scientific communities.

Aim of the Study: To determine the significance of MALDI image modality for tumour diagnosis.

Research Question: Is MALDI imaging modality significant for understanding tumour microenvironment?

Keywords: MALDI or Matrix Assisted Laser Desorption Ionisation; Tumour Diagnosis; Scientific Communities
\end{abstract}

\section{Introduction}

The histopathological analysis is considered to be one of the cornerstones in tumour diagnosis. At a microscopic level tissues are considered to be the primary harboring agents for a vast array of diseases and if we can study these tissues at cellular levels and understand the biomolecules and macromolecules involved we would be able to open a pandora's box into a new world of cellular microbiology. Over the years as tumour imaging systems have improved so has our understanding of the complex world of the tumour microenvironment, thereby preventing us from piling up the already existing heap of cancer burden. However, one must also remember that these imaging systems come with multiple disadvantages and are a major setback to understand that one cell amidst the $10^{\wedge} 14$ cells in our body which is the source for the origi- 
nation of the tumour, due to lack of our knowledge of the minute world of the tumour microenvironment and the biomolecules involved. In this paper, we have tried and reviewed a revolutionary system MALDI (i.e. Matrix-Assisted Laser Desorption/Ionization technique) which has proved to be a torchbearer to understand the complex world tumour microenvironment and the associated world of molecular cytology.

\section{Materials and Methods}

Various researches and studies have documented that the use of MALDI as an imaging modality to analyze tumour and its microenvironment is both specific and sensitive. With this fact in mind, a literature-based systematic review was carried out to fulfill the aim of the study. The study sample includes review and research articles based on databases from the COCHRANE collaboration as well as few other scientific libraries like Medline and Med-know, having undergone a definite Randomized Control Trial (RCT), to signify the title of the study. There were 40 articles initially taken and then all they underwent a randomized control trial post which 30 articles were selected for the study.

\section{Results}

MALDI has changed our entire concept of understanding the nuances of clinicopathological entities on a sub-microscopic level. Especially the intersection of mass spectrometric studies in the tumour world has allowed us to refine our therapeutic knowledge to improve our prognosis for the same.

MALDI is a versatile medium to demonstrate and study-specific tumour margins. Initially proposed by Chaurand, there are a lot of publications which support the idea that tissues histologically normal may have sub-molecular levels of indifference, MALDI allows the researchers to study these specific macromolecules from delineating the tumour tissues to normal tissues.

Moreover, as we know cancer cells continuously generate information in regards to the changes in the tumour microenvironment with the help of proteins, the detailed studying of these proteins under the broad class of proteomics would help us to describe the origin of tumours and therapeutic measures which could be taken to curb this menace and MALDI is the perfect tumour modality to serve the purpose.

The combination of MALDI with tumour diagnosis, typing, grading, and applications is perfect for the evaluation of small tissue samples (the entire process remains cost-effective and human bias is reduced). Moreover, this happens to be a rather effective option for the future as we move more towards minimally invasive techniques and the sizes for the available tissue samples from biopsies are becoming small.

MALDI have been time and again used to identify specific markers that would help the clinician to correlate with cancer progression in cases like preinvasive bronchial lesions, lung cancer, brain tumours, Barrett's adenocarcinoma, etc. The accuracy by which tumours could be graded as normal, pre-invasive, and invasive was $>90 \%$.

With the use of this technique we have revolutionized the study of drug delivery system as it has become easier to understand the macromolecules via the spectrometric analysis and how they tend to interact as metabolites with the tissue microenvironment

\section{Discussion}

\section{Background}

The etymological origin of the word MALDI can be traced back to the year 1985 [1] when Franz-Hillenkamp, Michael Karas, and their colleagues discovered that alanine (an amino-acid) could be ionized easily when mixed with another amino acid tryptophan and irradiated in presence of pulsed $266 \mathrm{~nm}$ laser, thus introducing the concept of matrix usage in studying micro-biomolecules. Similarly, Koichi Tanaka [2] of Shimadzu Co-operation had breakthrough research in a similar field around the year 1987 when he and his co-workers found out the technique of "Ultra-Fine Metal plus Liquid Matrix Technique". This technique used the combination of $30 \mathrm{~nm}$ cobalt particles in glycerol and ionized in presence of $337 \mathrm{~nm}$ nitrogen laser subsequently using this process he could ionize biomolecules as large as 34,472 Da (carboxypeptidase-A) thereby finally claiming his Nobel Prize for chemistry in the year 2002 [3].

Ever since then until now MALDI has changed our entire concept of understanding the nuances of clinico-pathological entities on a sub-microscopic level. Especially the intersection of mass spectrometric studies in the tumor world has allowed us to refine our therapeutic knowledge to improve our prognosis for the same. Today MALDI can measure a large number of analytes including protein, peptides lipids, and drugs. Moreover, the intersection of MALDI with a host of computer and software programs has al- 
lowed it to become more user friendly in the process of tumour detection. Time and again it has proved to be a versatile tool to not only study human pathology but also has been vividly used to describe to understand the microbiological world of plants, insects, and vertebrates [4-11] (including whole animals and human cells). Moreover, as we know tumour cells continuously generate information in regards to the changes in the tumour microenvironment with the help of proteins, the detailed studying of these proteins under the broad class of proteomics would help us to describe the origin of tumours and therapeutic measures which could be taken to curb this menace. MALDI is also an increasingly versatile technique and as we detail the review we would explain how this technique has also redefined our understanding of the organ systems as well [5-9].

\section{Detailed understanding of the working system of MALDI}

To better understand the impact of MALDI in cancer diagnosis we need to understand the detailed functioning of the system:

- Initially, as the process begins one has to ensure that the "Sample Tissue" [12] needs to be aptly prepared. Generally, the specimen could either be an un-fixed frozen sample or a paraffin-embedded tissue sample. In cases of frozen tissue sampling, the specimen calls for immediate storing at -80 degrees Celsius followed by rapid cutting to enable the study of protein, drugs, and other metabolites. While in the case of formalin-fixed and paraffin-embedded samples the given tissues need to be digested to allow the analysis of peptides only.

[One must remember that frozen samples are easier to be analyzed and imaged as they do not require multiple steps for sample preparation i.e. deparaffinization or antigen revival. However, handling of the frozen specimens has many associated disadvantages as there is a chance of continuous protein degradation during repeated freeze-thaw cycles and there needs to be a presence of expensive freezer to facilitate storage procedure].

- The specimen that needs to be investigated is called as an "Analyte". The entire process initiates with the selection of the specimen analyte which needs to be mixed with the "Matrix". Once the sample solution is prepared it is deposited in a sample plate called a "Target" (target is usually made up of polished or ground stainless steel).
The entire concept of the MALDI system is based on the matrix used with the analyte. The matrix is extremely important as it prevents the decomposition of the bio-macromolecule due to the intense ionization process (unlike its counterparts) [13].

There are 3 types of the matrix which could be considered for the process they are:

- Classical organic matrix: Derivatives of Benzoic acid or Cinnamic acid.

- Liquid crystalline matrix: Extremely useful in cases of soft ionization procedures.

- Inorganic matrix: Generally, graphite as it provides a weak background.

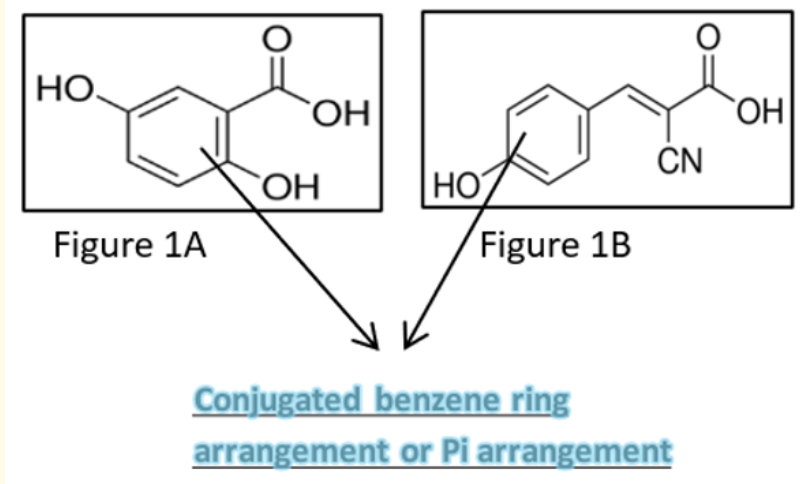

Figure 1

Given here are examples of 2, 5-Dihydroxybenzoic acid (Figure 1a) and $\alpha$-Cyano-4-hydroxycinnamic acid and (Figure $1 \mathrm{~b}$ ). Both of them are important matrix sources for MALDI procedure. Now the reason as to why do the analyte not decompose during ionization procedure is because of these matrices. In specific the conjugated PI or benzene ring arrangement in these matrices allows the matrix system to absorb the maximum energy in form of UV light thereby protecting the analyte so that it facilitate the ionic conversion of the analyte.

Once the sample solution is placed the solvent is allowed to evaporate thereby leaving behind a solid sample spot on the target which now needs to be analyzed. 
The target with the matrix and the analyte is now introduced into the spectrometer and once in the spectrometer they are placed in a vacuum and are subsequently struck via a UV LASER at a wavelength of $337 \mathrm{~nm}$ for 0.5 - 0.20 nano-seconds.

Post the striking; the UV rays are absorbed by the matrix molecules which prepare the analyte to get ablated from the target surface along with the analyte sample.

Now the analyte and matrix molecules get ionized into the gaseous phase, during this ablation process the analyte molecules are ionized usually via the process of Proton Transfer (i.e. $\mathrm{H}^{+}$transfer) via the matrix molecules. (The most common format is for the analyte molecule to carry a single charge). This is the initial linear model.

Now begins the next step i.e. calculation of the "Time of Flight" using time of flight spectrometry.

The time of the flight process accelerates the gaseous and ionized ion in a high voltage electric field; this field continuously imparts a constant Kinetic Energy to the ions. Now we know that the kinetic energy $=1 / 2 * \mathrm{~m}^{*} \mathrm{v}^{2}$, constant kinetic energy will allow the smallest of the ion to travel the fastest.

Assume that all the ions are univalent cations (i.e. with +1 charge) and hypothetically their masses are:

\begin{tabular}{|l|c|c|c|}
\hline \multicolumn{1}{|c|}{ Property } & $\begin{array}{c}\text { Macromolecule } \\
\text { A }\end{array}$ & $\begin{array}{c}\text { Macromolecule } \\
\text { B }\end{array}$ & $\begin{array}{c}\text { Macromol- } \\
\text { ecule C }\end{array}$ \\
\hline $\begin{array}{l}\text { Mass of the } \\
\text { macromolecule }\end{array}$ & $1 \mathrm{KDa} / \mathrm{z}$ & $2 \mathrm{KDa} / \mathrm{z}$ & $4 \mathrm{kDa} / \mathrm{z}$ \\
\hline
\end{tabular}

Table 1

If we go by the above-mentioned logic under the Time of Flight condition the smaller macromolecule i.e. of $1 \mathrm{KDa}$ would be accelerated the fastest to around $54 \mathrm{~km} / \mathrm{sec}$, while the macro-molecule B would be accelerated at around $38 \mathrm{~km} / \mathrm{sec}$ approximately and the largest one would be accelerated at around $27 \mathrm{~km} / \mathrm{sec}$.

Now forwarding the hypothetical study experiment the smallest ion of $1 \mathrm{KDa}$ would reach the detector fastest at around 28 microseconds in a $1.5 \mathrm{mts}$ flight, following to which the 2 KDa macromolecule would take 39 microseconds to cover the same distance.
The largest macromolecule would take 56 microseconds to cover the reach.

[Note: The entire calculation was done on a hypothetical perspective to outline the functioning of the time of flight principle in the MALDI spectrometry procedure].

Now a graph is plotted under a known fixed Kinetic Energy within the electric field.

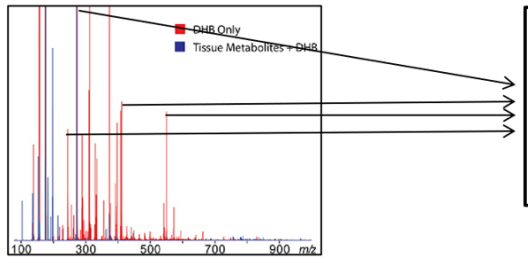

Using the above technique a graph is thus plotted against the axis of time. Now the graph will have multiple peaks in it and each peak would correspond to the mass of the particle along the time axis starting from the ionization moment.

Graph: The graph is a hypothetical graph to explain the mass spectrum analysis. Image Source: MALDI-Mass Spectrometric Imaging for the Investigation of Metabolites in Medicago truncatula Root Nodules by - Erin Gemperline and Lingjun Li- University of Wisconsin-Madison).

Another mode which is also present in the MALDI spectrometer is the Reflector Mode. In this mode the particles are diverted towards a second detector, Now there are two advantages to this:

A. This process extends the flight distance.

B. The reflector also focuses on the masses of the macromolecule.

(Finally, the two combinations result in a higher resolution than the one obtained in the above linear mode).

After the MALDI imaging procedure (in cases of tumour tissue analysis) the very same tissue sample can be stained with H\&E and then finally registered with the mass spectrometric analysis.

Bio-informatics tools such as MALDI Vision [14] are then used for data interpretation, processing, and visualization while analyzing the spatial distribution of the individual ions in a given tissue sample. The mass signals are detected and observed via color intensity maps. In the meantime, these maps assign molecular pat- 
terns to the cell types present in the tissue sample. These signals from the colour maps allow for easy detection of patterns that represent the distribution of the tissues and the molecules of interest.

The bio-informatics software not only allow detection of specific molecule type but also assist in generating specific molecular signatures concerning a given cell type- this in principle is known as “Tissue Microdissection" [15,16].

In the MALDI imaging system tissue microdissection is performed virtually via definite regions-of-interests or (ROI) [17] and the bioinformatics software can then extract specific mass spectrometric information regarding these specific ROIs. Now, this has a huge benefit that all tissue parts can be easily examined at once.

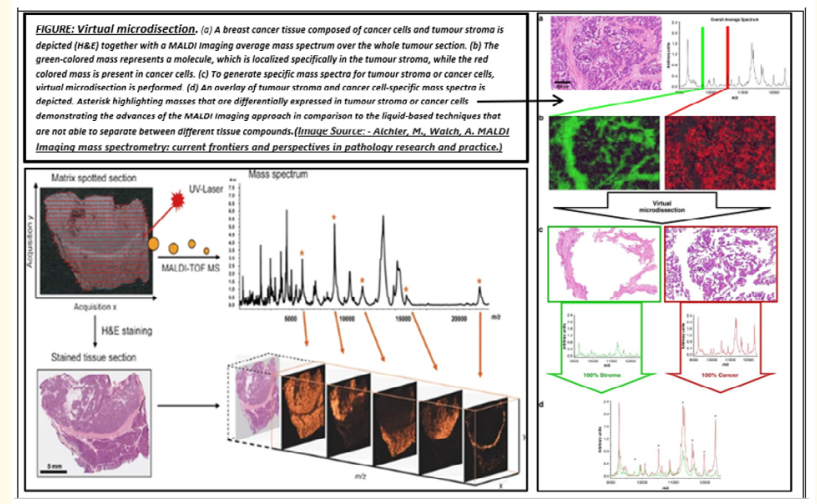

Figure 2: Principle of MALDI imaging mass spectrometry (Image Source: Aichler, M., Walch, A. MALDI Imaging mass spectrometry: current frontiers and perspectives in pathology research and practice. (https://doi.org/10.1038/ labinvest.2014.156).

Now there is specific information we can all obtain from the MALDI system regarding tumour diagnosis they can be broadly studied under the following subheadings.

\section{Applications of MALDI}

While the identification of the biomarkers is a predictable improvement in the scope of tumour prognosis the classification of the patients into specific treatment groups and predicting the response of the individual treatments are extremely important to maximize the survival rates of these patients. With this imaging modality being continuously used it has served an important purpose for the study of new proteins, for instance, a study had shown that gastric cancer had specific protein signatures (in spe-

\begin{tabular}{|c|c|}
\hline $\begin{array}{l}\text { Tumour } \\
\text { Margins }\end{array}$ & $\begin{array}{l}\text { MALDI is a versatile medium to demonstrate and } \\
\text { study-specific tumour margins. Initially proposed } \\
\text { by Chaurand,[18] there are a lot of publications } \\
\text { that support the idea that tissues histologically } \\
\text { normal may have sub-molecular levels of } \\
\text { indifference. For instance, it has been seen in } \\
\text { ovarian cancer that specific proteins such as } \\
\text { plastin } 2 \text { and peroxiredoin } 1 \text { are found in the } \\
\text { areas delineating the tumour cells. Similarly, it has } \\
\text { been seen that proteins involved in the } \\
\text { mitochondrial electron transport systems are } \\
\text { constantly under-expressed in cases of tumours } \\
\text { in comparison to the histo-pathologically normal } \\
\text { tissues delineating the tumour cells. Thereby } \\
\text { with these conclusions, one can easily find out the } \\
\text { specific sites which would delineate the tumour } \\
\text { and help the clinician to create specific molecular } \\
\text { signatures for future tumour references while } \\
\text { studying their interfaces for the same [19]. }\end{array}$ \\
\hline $\begin{array}{l}\text { Tumour } \\
\text { Typing }\end{array}$ & $\begin{array}{l}\text { As we move towards a future dominated with } \\
\text { minimally invasive techniques, the sample tissue } \\
\text { sizes for biopsies are also going to reduce } \\
\text { overtime. However one must remember that for } \\
\text { detection of a given specific tumour it is } \\
\text { important for us to identify a huge number of } \\
\text { proteins hence effective and specific techniques } \\
\text { are required for the same. } \\
\text { MALDI promises to tick the right boxes, as a very } \\
\text { small tissue sample is required for the full pro- } \\
\text { cedure and the further sample could be available } \\
\text { for better molecular classification and mutation } \\
\text { screening (e.g. lung tumour). The combination } \\
\text { of this technique with tumour diagnosis, typing, } \\
\text { grading, and applications is perfect for the } \\
\text { evaluation of small tissue samples (moreover the } \\
\text { entire process remains cost-effective and human } \\
\text { bias is reduced) [19-22]. }\end{array}$ \\
\hline $\begin{array}{l}\text { Tumour } \\
\text { Grading } \\
\text { And } \\
\text { Prognosis }\end{array}$ & $\begin{array}{l}\text { MALDI has been time and again used to identify } \\
\text { specific markers that would help the clinician to } \\
\text { correlate with cancer progression in cases like } \\
\text { preinvasive bronchial lesions, lung cancer, brain } \\
\text { tumours, Barrett's adenocarcinoma, etc. [23-29]. } \\
\text { The accuracy by which tumours could be graded } \\
\text { as normal, pre-invasive, and invasive was }>90 \% \\
\text { [30]. It has been seen that in some tumours such } \\
\text { as the myxoid sarcomas high graded tumours } \\
\text { could be easily separated from the low-grade } \\
\text { tumours. When used in conjunction with } \\
\text { techniques such as proteomic tissue profiling } \\
\text { the grading of non-invasive papillary urethral } \\
\text { neoplasia [31] was superior. Besides grading this } \\
\text { technique has also been supportive to understand } \\
\text { the early stage diseases and predict specific } \\
\text { proteomic signatures. }\end{array}$ \\
\hline
\end{tabular}

Table 2 
cific cases of unfavorable survival rates) namely: S100-A6, HNP-1 and CRIP1 however earlier never had any protein detecting modality explained the presence of CRIP1. Moreover, it was found out in the study of Barrett's carcinoma [32] that all the individuals with favorable clinical responses had specific proteomic signatures, unlike the ones who didn't respond to the treatment. Moreover, it also found out that COX7A2 protein expression could be used to discriminate between clinical responders and non-responders to cisplatin [32] treatment similar findings concerning the protein study was also found out in many other studies, thereby proving the use of MALDI in the protein identification, stratification, and responses. Post translation modifications in the field of proteomics can be easily studied with MALDI specifically in cases of histonic modifications seen in the cases of hepatocellular carcinomas [33]. This study also emphasized the study of histone-4 modifications were common in cases of microvascular invasion. The scientific community is well aware of the fact that the two carcinomas with poor prognosis are the gastric and hepatocellular cancer, both of which lack any form of early markers of malignancy. A proper study of such tissue sample biopsies was able to identify specific proteomic patterns that could easily help to differentiate between the healthy and cancerous spectrum. Recently the scientific community has also been able to understand the conversion of cirrhosis to hepatocellular carcinoma using MALDI, the scientist has found out that increased expression of truncated monomeric ubiquitin was an important factor to determine the progression. The technique to use formalin-fixed paraffin-embedded (FFPE) tumour tissue sample is a recent field of study to screen breast cancer and pancreatic cancer specimen. It has been seen that using this technique in adjunct to the MALDI technique not only has it been easier to discriminate between the breast and pancreatic cancer specimens but also determine their specific protein spectral profile to accurately determine the origin of the tumour. Another field using a similar technique in the study of FFPE microarray of pancreatic tumours in combination with principal component analysis -discriminant analysis or the PCA-DA showed how easy was it to classify peptide profiles for pancreatic tumours in form of stages while using the MALDI technique for the same. This goes on to show how much MALDI could influence the understanding of classification and grading of tumours beyond their overall histopathological and morphological basis. In many cases, it has been seen that the drugs can be labeled and imaged using the positron imaging technique however it is yet unknown how would these labeling impacts the physical proper- ties of the drugs or to understand how the drug metabolizes, such studies could be done using the MALDI technique. Effects of orally administered afatinib, erlotinib, and sorafenib I.r.t to vascularisations seen in squamous cell carcinoma could be studied through the process of MALDI. Similarly, an examination of drug metabolite distribution in tissues in cases of colon-adenocarcinomas such as drug sunitinib can be studied; another study is of injected irinotecan and its metabolite SN-38 is also under MALDI study for colorectal cancer.

Outline of MALDI based studies in specific organs and organ systems

\begin{tabular}{|c|c|}
\hline $\begin{array}{l}\text { Organ } \\
\text { entity }\end{array}$ & Content/study findings $[34,35]$ \\
\hline Brain & $\begin{array}{l}\text { Proteins and peptide sequences concerning } \\
\text { glial brain tumors, identification of new protein } \\
\text { sequences in cases of gliomas which could predict } \\
\text { short and long term prognostic factors, grading and } \\
\text { staging of different types of meningioma, } \\
\text { demonstration of the transit of drugs via the } \\
\text { blood-brain barriers, understanding more about } \\
\text { the P13K-inhibitors in cases of glioblastomas. }\end{array}$ \\
\hline Breasts & $\begin{array}{l}\text { Invasive studying and imaging of breast cancer and } \\
\text { peritumoral stroma, comparison studies of protein } \\
\text { signals of inter-tumoral and extra tumoral stroma } \\
\text { in cases of breast cancers, protein identification to } \\
\text { predict Her- } 2 \text { range in cases of breast carcinomas } \\
\text { along with cysteine-rich intestinal proteins. Novel } \\
\text { approaches to study the combination of MALDI I } \\
\text { r.t to tumour classifications, study the presence of } \\
\text { choline metabolites in viable and necrotic tumour } \\
\text { regions in samples of breast cancer xenograft } \\
\text { models, determination of lymph node status in } \\
\text { cases of breast cancer and to study their interaction } \\
\text { with the given chemotherapy. }\end{array}$ \\
\hline Oral & $\begin{array}{l}\text { Using MALDI to study the biopsy specimens } \\
\text { involving the cases of squamous cell carcinomas }\end{array}$ \\
\hline $\begin{array}{l}\text { Oesoph- } \\
\text { agus }\end{array}$ & $\begin{array}{l}\text { Using the MALDI technique to study and detect } \\
\text { COX7A2, TAGLN2 \& S100-A10 as markers in cases } \\
\text { of Barrett's adenocarcinoma. }\end{array}$ \\
\hline Stomach & $\begin{array}{l}\text { Using the MALDI technique to distinguish gastric } \\
\text { cancer from normal mucosa and studying the } \\
\text { signals defensins and calgranulins, to study the } \\
\text { histone H4 differentiation factors, identifying } \\
\text { S100A8 and S100A9 regulators for lymph node } \\
\text { metastasis of gastric cancer. }\end{array}$ \\
\hline
\end{tabular}




\begin{tabular}{|c|c|}
\hline Colon & $\begin{array}{l}\text { Helping to establish algorithms for six important } \\
\text { and common tumours along with studying the rates } \\
\text { and chances of liver metastasis of colonic cancer. }\end{array}$ \\
\hline Pancreas & $\begin{array}{l}\text { Discovering the } \mathrm{m} / \mathrm{z} \text { species for the pancreas under } \\
\text { normal conditions, intraepithelial neoplasia in the } \\
\text { pancreas, and further study of the intraductal } \\
\text { papillary mucinous neoplasms, to study and } \\
\text { analyze glucose-regulated proteins in the } \\
\text { pancreatic adenocarcinoma. }\end{array}$ \\
\hline Liver & $\begin{array}{c}\text { Determining and protein profiling for } \\
\text { hepatocellular carcinomas and liver cirrhosis. }\end{array}$ \\
\hline Lung & $\begin{array}{l}\text { Determining protein factor peaks in the lung } \\
\text { cancer histology to distinguish primary cancer } \\
\text { from metastatic ones. Also, pre-invasive lesions } \\
\text { and proteomic profiling is done for cases of lung } \\
\text { cancers, Study the effects of erlotinib, gefitinib, and } \\
\text { tiotropium I .r.t. to the tumor micro-environment. } \\
\text { Non-small cell cancers could also be classified } \\
\text { according to MALDI lipid profiling. }\end{array}$ \\
\hline $\begin{array}{l}\text { Lympho- } \\
\text { mas }\end{array}$ & $\begin{array}{l}\text { MALDI could be used to discriminate between } \\
\text { Hodgkin's lymphoma and lymphadenitis with a } \\
\text { specificity of } 83.92 \%-89.37 \% \text {. }\end{array}$ \\
\hline Skin & $\begin{array}{l}\text { MALDI could be used to select the protein } \\
\text { signatures for survival and recurrences in } \\
\text { malignant melanoma, it could also be used to } \\
\text { differentiate Spitz nevi from Spitzoid malignant } \\
\text { melanoma via MALDI, could be used to determine } \\
\text { the identification of vemurafenib in cases of } \\
\text { malignant melanoma }\end{array}$ \\
\hline Thyroid & $\begin{array}{l}\text { MALDI could be successfully used to identify S100A } \\
\text { 10, thioredoxin as biomarkers for cases of papillary } \\
\text { thyroid carcinomas with the presence of lymph } \\
\text { node metastasis could be used to detect ribosomal } \\
\text { protein P2 specificity in cases of papillary thyroid } \\
\text { cancer, to help characterization of the proteomic } \\
\text { profile in cases of medullary thyroid carcinoma. }\end{array}$ \\
\hline $\begin{array}{l}\text { Sarco- } \\
\text { mas }\end{array}$ & $\begin{array}{c}\text { To identify proteins and lipids in myxoid sarcomas } \\
\text { specific to given tumour types showing intra-tumor } \\
\text { heterogeneity. }\end{array}$ \\
\hline Prostate & $\begin{array}{l}\text { MALDI allows discrimination of cancerous and } \\
\text { non-cancerous prostatic tissues on basis of protein } \\
\text { profiling, MALDI could also be used to identify } \\
\text { cancerous or non-cancerous tissues on basis of } \\
\text { mitogen-activated protein kinase, detection of } \\
\text { tumor favorable phenotypes, a prolonged type of } \\
\text { relapse. }\end{array}$ \\
\hline
\end{tabular}

\begin{tabular}{|l|c|}
\hline Ovary & $\begin{array}{c}\text { MALDI could be used to understand and investigate } \\
\text { the interface between serous ovarian carcinoma } \\
\text { from the normal tissues, identification of 11S } \\
\text { proteome activator complex, and studying of } \\
\text { regulator alpha fragment to study biomarkers for } \\
\text { ovarian cancer, integrated study of the } \\
\text { transcriptomic and lipidomic analysis of sulfatides } \\
\text { in cases of ovarian cancer. }\end{array}$ \\
\hline Bladder & $\begin{array}{c}\text { MALDI in association with proteomic tissue } \\
\text { profiling has helped to advance the frontiers of } \\
\text { grading non-invasive papillary urothelial neoplasia, } \\
\text { evaluating signals associated with tumour } \\
\text { aggressiveness, and analyzing the phenotype and } \\
\text { histologic growth pattern has made it easier to } \\
\text { study cell proliferation in cases of bladder cancers. }\end{array}$ \\
$\begin{array}{c}\text { MALDI can be used to analyze the tumour margins } \\
\text { in cases of renal cell carcinomas, detection, and } \\
\text { analysis of race-specific profiles in cases of Wilms } \\
\text { tumours, etc. }\end{array}$ \\
\hline Kidney
\end{tabular}

Table 3

\section{Conclusion}

The applications of MALDI have already generated enough ripples in the research community; some of the spectrometric techniques are been currently applied and implemented to study the tumour microenvironment and the pathogenesis. Not only has this technique revolutionized the way we have studied cancer but its uses have been felt far and wide for instance MALDI-BIOTYPE provides the characterization of bacterial cell cultures via documenting molecular profiles and making databases for proteomic profile spectra's to identify unknown microbes concerning the species level. Currently, diagnostic procedures in pathology employ the use of histology, histochemistry, immunohistochemistry, and molecular pathology however it has been estimated that in the future these techniques would be used as an adjunct to MALDI proteomic analysis to improve diagnostic accuracy for the same. Currently, the MALDI system has already got FDA approval and also CE certification. MALDI is also expected to replace many histochemical techniques such as periodic acid-Schiff and Prussian blue reaction as methods which are used to highlight connective tissues. Further, the installation of the bio computational tools in association with MALDI would allow better bio-statistical evaluation for determining molecular signals. Moreover, with the use of this technique, we have revolutionized the study of drug delivery system as it has 
become easier to understand the macromolecules via the spectrometric analysis. In all MALDI is continuously proving to be an exceptional tool for exploring the world of tissue-based research and studying the tumour microenvironment and biology.

\section{Bibliography}

1. Karas M., et al. "Influence of the Wavelength in High-Irradiance Ultraviolet Laser Desorption Mass Spectrometry of Organic Molecules". Analytical Chemistry 57.14 (1985): 2935-2939.

2. Tanaka K., et al. "Protein and Polymer Analyses up to m/z 100 000 by Laser Ionization Time-of flight Mass Spectrometry". Rapid Communications in Mass Spectrometry (1988).

3. Markides K and Gräslund A. "Advanced information on the Nobel Prize in Chemistry 2002" (PDF)". The Royal Swedish Academy of Sciences (2002).

4. Patel R. "MALDI-TOF mass spectrometry: transformative proteomics for clinical microbiology". Clinical Chemistry 59 (2013): 340-342.

5. Clark AE., et al. "Matrix-assisted laser desorption ionizationtime of flight mass spectrometry: a fundamental shift in the routine practice of clinical microbiology". Clinical Microbiology Reviews 26 (2013): 547-603.

6. Moore JL., et al. "Advanced mass spectrometry technologies for the study of microbial pathogenesis". Current Opinion in Microbiology 19C (2014): 45-51.

7. Kueger S., et al. "Highresolution plant metabolomics: from mass spectral features to metabolites and from whole-cell analysis to subcellular metabolite distributions". The Plant Journal 70 (2012): 39-50.

8. Schoenian I., et al. "Chemical basis of the synergism and antagonism in microbial communities in the nests of leaf-cutting ants". Proceedings of the National Academy of Sciences of the United States of America 108 (2011): 1955-1960.

9. Chaurand P., et al. "From whole-body sections down to cellular level, multiscale imaging of phospholipids by MALDI mass spectrometry". Molecular and Cellular Proteomics 10 (2011): 0110.004259.

10. Trim PJ., et al. "Matrix-assisted laser desorption/ionizationion mobility separation-mass spectrometry imaging of vin- blastine in whole body tissue sections". Analytical Chemistry 80 (2008): 8628-8634.

11. Reyzer ML., et al. "Direct molecular analysis of whole-body animal tissue sections by MALDI imaging mass spectrometry". Methods in Molecular Biology 656 (2010): 285-301.

12. MALDI TOF imaging mass spectrometry in clinical pathology: a valuable tool for cancer diagnostics (Review) Jörg Kriegsmann1-3, Mark Kriegsmann4 and Rita Casadonte3 1MVZ for Histology, Cytology and Molecular Diagnostics, Trier; 2Institute for Molecular Pathology; 3Proteopath GmbH, Trier; 4Institute for Pathology, University of Heidelberg, Heidelberg, Germany.

13. Recent Developments of Useful MALDI Matrices for the Mass Spectrometric Characterization of Lipids [Jenny Leopold, Yulia Popkova, Kathrin M. Engel, and Jürgen Schiller*]

14. Maldivision:- A Comprehensive Data Processing and Visualization Tool For MALDI Imaging Mass Spectrometric Data.

15. Emmert-Buck MR., et al. "Laser capture microdissection". Science 274 (1996): 998-1001.

16. Espina V., et al. "Laser capture microdissection technology". Expert Review of Molecular Diagnostics 7 (2007): 647-657.

17. Norris JL and Caprioli RM. "Analysis of tissue specimens by matrix-assisted laser desorption/ionization imaging mass spectrometry in biological and clinical research". Chemical Reviews 113 (2013): 2309-2342.

18. Chaurand P., et al. "Proteomics in diagnostic pathology: profiling and imaging proteins directly in tissue sections". The American Journal of Pathology 165 (2004): 1057-1068.

19. Agar JN. "Recent advances in single-cell MALDI mass spectrometry imaging and potential clinical impact". Expert Reviews on Proteomics 8 (2011): 591-604.

20. Morita Y., et al. "Imaging mass spectrometry of gastric carcinoma in formalin-fixed paraffin embedded tissue microarray". Cancer Science 101 (2010): 267-273.

21. Groseclose MR., et al. "High-throughput proteomic analysis of formalin-fixed paraffin-embedded tissue microarrays us- 
ing MALDI imaging mass spectrometry". Proteomics 8 (2008): 3715-3724.

22. Meding S., et al. "Tumor classification of six common cancer types based on proteomic profiling by MALDI imaging". Journal of Proteome Research 11 (2012): 1996-2003.

23. Rahman SM., et al. "Lung cancer diagnosis from proteomic analysis of preinvasive lesions". Cancer Research 71 (2011): 3009-3017.

24. Schwartz SA., et al. "Proteomic-based prognosis of brain tumor patients using direct-tissue matrix-assisted laser desorption ionization mass spectrometry". Cancer Research 65 (2005): 7674-7681.

25. Lemaire R., et al. "Specific MALDI imaging and profiling for biomarker hunting and validation: fragment of the $11 \mathrm{~S}$ proteasome activator complex, Reg alpha fragment, is a new potential ovary cancer biomarker". Journal of Proteome Research 6 (2007): 4127-4134.

26. Flatley B., et al. "MALDI mass spectrometry in prostate cancer biomarker discovery". Biochimica et Biophysica Acta 1844 (2014): 940-949.

27. Tissue profiling for the improvement of grading of noninvasive papillary urothelial neoplasia". Clinical Biochemistry 45 (2012): 7-11.

28. Meding S., et al. "Tumor classification of six common cancer types based on proteomic profiling by MALDI imaging". Journal of Proteome Research 11 (2012): 1996-2003.

29. Nipp M., et al. "S100-A10, thioredoxin, and S100-A6 as biomarkers of papillary thyroid carcinoma with lymph node metastasis identified by MALDI imaging". Journal of Molecular Medicine 90 (2012): 163-174.

30. Rahman SM., et al. "Lung cancer diagnosis from proteomic analysis of preinvasive lesions". Cancer Research 71 (2011): 3009-3017.

31. Oezdemir RF., et al. "Proteomic tissue profiling for the improvement of grading of noninvasive papillary urothelial neoplasia". Clinical Biochemistry 45 (2012): 7-11.
32. Aischer M., et al. "Clinical response to chemotherapy in oesophageal adeno-carcinoma patients is linked to defects in the mitochondria". The Journal of Pathology (2013).

33. Kim HK., et al. "Gastric cancer specific protein profile identified using endoscopic biopsy samples via Maldi Mass Spectrometry (2010).

34. Michaela Aichler and Axel Walch. "MALDI Imaging mass spectrometry: current frontiers and perspectives in pathology research and practice".

35. Jörg Kriegsmann., et al. "MALDI TOF imaging mass spectrometry in clinical pathology: a valuable tool for cancer diagnostics (Review)".

\section{Assets from publication with us}

- Prompt Acknowledgement after receiving the article

- Thorough Double blinded peer review

- Rapid Publication

- Issue of Publication Certificate

- High visibility of your Published work

Website: www.actascientific.com/

Submit Article: www.actascientific.com/submission.php Email us: editor@actascientific.com

Contact us: +919182824667 